\title{
Evaluation of Foveal Thickness and Macular Choroidal Thickness with Optical Coherence Tomography in Behcet's Disease
}

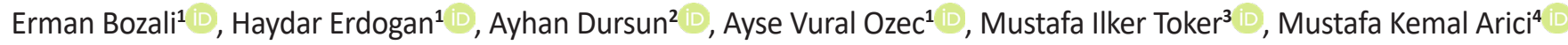 \\ ${ }^{1}$ Sivas Cumhuriyet University School of Medicine Department of Ophthalmology, Sivas, Turkey \\ ${ }^{2}$ Ankara Maya Eye Hospital, Ankara, Turkey \\ ${ }^{3}$ University of Health Sciences Ulucanlar Eye Training and Research Hospital, Ankara, Turkey \\ ${ }^{4}$ Memorial Atasehir Hospital, Istanbul, Turkey \\ Correspondence Author: Erman Bozali \\ E-mail: ermanbozali@gmail.com \\ Received: $05.08 .2020 \quad$ Accepted: 24.04 .2021
}

\begin{abstract}
Objective: To evaluate the foveal thickness and macular choroidal thickness on patients who were diagnosed with Behcet's Disease (BD).

Methods: A total of 60 patients were included in this prospective cross-sectional study. Patients were divided into two groups. Group 1 consisted of 30 patients who were diagnosed with BD and Group 2 consisted of 30 healthy controls. Detailed ophthalmological examination was performed on both groups and foveal thickness and macular choroidal thickness were measured with Spectral-Domain Optical Coherence Tomography (SD-OCT). To measure the choroidal thickness enhanced depth imaging OCT (EDI-OCT) technique was used.

Results: Mean foveal thickness in BD patients was $216.06 \pm 53.14 \mu \mathrm{m}$ and mean subfoveal choroidal thickness was $363.21 \pm 85.22 \mu \mathrm{m}$. Mean foveal thickness and subfoveal choroidal thickness in healthy controls was $211.65 \pm 16.60 \mu \mathrm{m}$ and $352.83 \pm 87.11 \mu \mathrm{m}$ respectively. There was no statistical significance between patients with $\mathrm{BD}$ and patients of the control group regarding foveal and subfoveal choroidal thickness. However, anatomical deformation of Ellipsoid Zone structure in OCT had the most effect on visual acuity $(p=0.001)$.
\end{abstract}

Conclusion: This study shows that there was no statistically significant difference in terms of foveal thickness and macular choroidal thickness in patients with BD.

Keywords: Behcet's disease, optical coherence tomography, choroidal thickness, inflammation.

\section{INTRODUCTION}

Behcet's disease (BD) is a systemic immune-mediated occlusive vasculopathy whose etiology and pathogenesis are not fully elucidated. Oral aphthous stomatitis, genital ulcerations, skin lesions, and ocular disease are evaluated as major findings (1). Ocular involvement is seen approximately in $60-80 \%$ of the patients. Anterior and posterior ocular involvement often proceed to iridocyclitis with hypopyon and retinal vasculitis (2). Hence, uveitis seen in BD is shown to be affecting choroid due to diffuse infiltration of inflammatory cells into the choroid (3). Retinal vasculitis with anterior, posterior involvement, or panuveitis are characteristics of the disease. Fundoscopic changes due to posterior segment involvement can significantly affect visual acuity (4-8). Besides clinical examination, the evaluation of the posterior segment involvement in $\mathrm{BD}$ can be practiced by fundus fluorescein angiography (FFA), indocyanine green angiography (ICA), ultrasonic biomicroscopy (UBM), multifocal electroretinogram (mfERG), and SD-OCT (9-13). The choroid, which is crucial for the retina to function properly, has up to $85 \%$ of the ocular blood flow. A great quantity of diseases including central serous chorioretinopathy, age-related macular degeneration, and chorioretinal inflammatory diseases has an impact on choroidal thickness $(14,15)$. Enhanced depth imaging (EDI) technique has been a good turn for physicians evaluating choroidal tissue with OCT. Since this imaging technique is widely accepted and used by physicians all over the world, understanding the morphological changes in choroid are easier not only in healthy population but also pathological diseases and conditions such as central serous chorioretinopathy, high myopia, polypoidal choroidal vasculopathy, age-related macular degeneration and VogtKoyanagi-Harada (VKH) disease (16-20). Furthermore, Park et al. revealed long term changes in choroidal thickness in Behçet's disease following up patients at least 24 months. According to that study, choroidal thickness decreased over time in BD patients and it was associated with the length of active inflammation (21). This present study was conducted 
to measure foveal thickness and macular choroidal thickness using Enhanced Depth Imaging technique of spectral domain OCT (SD-OCT) in patients diagnosed with Behcet's disease and to compare it with healthy controls in the same age group.

\section{METHODS}

In this prospective cross-sectional study, 60 eyes of $30 \mathrm{BD}$ patients with active, inactive, and no ocular involvement older than 18 years of age and 60 eyes of 30 age and sexmatched healthy controls were included. All individuals agreed to sign an informed consent. This study was conducted in accordance with the principles of the Helsinki Declaration. Patients who had a history of intraocular surgery, glaucoma, or any other co-existing ocular pathologies and systemic disease and patients who had a spherical equivalent refractive error of more than \pm 5.00 diopters were excluded from this study. This study was approved by the Clinical Research Ethics Committee of Cumhuriyet University School of Medicine on 11.11.2014 and numbered as 2014-11/03. Complete ophthalmological examination of patients including best corrected visual acuity (BCVA), slitlamp biomicroscopy, non-contact tonometry to measure intraocular pressure, fundoscopy after pupil dilatation, and Spectral Domain-OCT (SD-OCT) scanning with RS-3000 Advance (Nidek Co., Ltd, Gamagori, Japan) was performed. All OCT measurements of the patients were performed between 9 and 12 am. Macular anatomy was evaluated with SD-OCT. The presence of ERM, internal and external retinal layers, especially ELM, Ellipsoid Zone, RPE-BM complex were examined, foveal thickness and subfoveal choroidal thickness was measured as well as choroidal thickness of nasal and temporal of the fovea. To evaluate the macular anatomy, an area of $12 \mathrm{~mm}$ was examined by selecting the ultrafine quality in Macula Line choroidal mode of the OCT device. With the Tracing HD plus feature, 120 sections of the Scanning Laser Ophthalmoscope (SLO) image was captured. Using Enhanced Depth Imaging OCT (EDI-OCT), subfoveal, nasal, and temporal macular choroidal thickness was measured manually with the measurement tool of built-in software based on the distance between the lowest part of the RPE / BM complex and the choroidoscleral junction. Manual method was used to measure foveal thickness by marking the distance between the lowest part of the RPE-BM complex and the foveal pit. In this study, the demographic data, clinical ophthalmological examination findings, macular anatomy, observing the structural integrity of the Ellipsoid Zone and RPE-BM complex with SD-OCT and their effects on BCVA were evaluated alongside the evaluation of foveal thickness and subfoveal, $1000 \mu \mathrm{m}$ nasal and temporal choroidal thicknesses with OCT in both groups.

\subsection{Statistical Analysis}

The data analysis of this study was performed using the SPPS version 22 (IBM Statistical Package for the Social Sciences Statistics; New York, USA). In independent groups, the significance test of the difference between the two means was used when the parametric test assumptions were fulfilled. Kruskal-Wallis test, the Mann Whitney $U$ test, and the Chi-square tests were used when the parametric test assumptions were not fulfilled. The mean value of the continuous variables is presented as mean \pm standard deviation (SD). A value of $p<0.05$ was considered statistically significant.

\section{RESULTS}

Of 30 Behcet's patients, 11 (36.7\%) were male and 19 (63.3\%) were female. The mean age of the patients was $36.16 \pm 11.85$ years (19-60 years). The mean age of diagnosis with BD was $28.60 \pm 8.83$ years. The control group consisted of 30 healthy subjects. Of the 30 patients in the control group, 15 were male (50\%), 15 were female (50\%), and the mean age was $35.10 \pm$ 7.58 years ( $20-65$ years) in the control group. Demographics and treatment modalities are presented in Table 1. Regarding mean age and gender, no statistical significance was found between groups $(p \geq 0.05)$. All 30 patients with BD (100\%) were receiving systemic medical treatment at the time of participation in the study. Twenty-nine patients (96.6\%) were on colchicine, 11 were on azathioprine (36.6\%), 10 (20\%) were on steroids and $5(23.3 \%)$ were on cyclosporine. The right eye of 4 patients (13.3\%), the left eye of 5 patients (\%16.6) were involved leading to unilateral ocular involvement in 9 patients (30\%) in total. Seven patients (33.3\%) had bilateral ocular involvement.

Table 1. Demographic characteristics of $B D$ patients and control group

\begin{tabular}{|l|c|c|c|}
\hline & BD group (n=30) & $\begin{array}{c}\text { Control group } \\
(\mathbf{n = 3 0 )}\end{array}$ & P value \\
\hline Age (Mean \pm SD) & $36.16 \pm 11.85$ & $35.10 \pm 7.58$ & $p=0.68$ \\
\hline Sex (male/female) & $11 / 19$ & $15 / 15$ & $p \geq 0.05$ \\
\hline $\begin{array}{l}\text { Mean Age of Diagnosis } \\
\text { (Mean } \pm \text { SD) }\end{array}$ & $28.60 \pm 8.83$ & - & - \\
\hline Treatment & \multicolumn{3}{|l|}{} \\
\hline Colchicine & $96.6 \%(n=29)$ & - & - \\
\hline Azathioprine & $36.6 \%(n=11)$ & - & - \\
\hline Corticosteroids & $20 \%(n=10)$ & - & - \\
\hline Cyclosporine & $23.3 \%(n=5)$ & - & - \\
\hline
\end{tabular}

$B D$ : Behçet's Disease

Best corrected visual acuity and SD-OCT measurements of the groups are shown in Table 2. The mean BCVA of all $B D$ patients was $0.92 \pm 0.23$. There was 1 eye (1.66\%) with BCVA lower than 0.1, 3 eyes (5\%) with BCVA between 0.1$0.3,2$ eyes (3.33\%) with BCVA between 0.4-0.6, and 54 eyes with BCVA equal or higher than 0.7. There was no statistical difference between genders regarding BCVA ( $p>0.05)$. All eyes in the control group had normal visual acuity. When 
the BCVA of the two groups was compared, the difference between groups was statistically significant $(p=0.012)$, but the difference was not significant when subfoveal, nasal, temporal choroidal thickness, and foveal thickness were compared. Comparison of BCVA regarding OCT measurements revealed a statistically significant difference $(p<0.05)$. The difference between eyes with normal OCT findings, eyes with Ellipsoid Zone defect, and eyes with both Ellipsoid Zone and RPE-BM defects were found to be statistically significant $(p=0.001)$. The difference between eyes with normal OCT findings, RPE-BM defect, and ERM was not statistically significant $(p>0.05)$.

Table 2. Comparison of best corrected visual acuity and SD-OCT values in patients with Behcet's disease and control group

\begin{tabular}{|l|c|c|c|} 
& BD group $(\mathbf{n = 3 0 )}$ & $\begin{array}{c}\text { Control group } \\
(\mathbf{n}=30)\end{array}$ & P value \\
\hline BCVA & $0.92 \pm 0.23$ & $1.00 \pm 0.00$ & $\mathrm{p}=0.012^{*}$ \\
\hline $\begin{array}{l}\text { Subfoveal choroidal } \\
\text { thickness }(\boldsymbol{\mu m})\end{array}$ & $363.21 \pm 85.22$ & $352.83 \pm 87.11$ & $\mathrm{p}=0.51$ \\
\hline $\begin{array}{l}\text { Nasal choroidal } \\
\text { thickness }(\boldsymbol{\mu m})\end{array}$ & $331.61 \pm 81.06$ & $329.63 \pm 84.04$ & $\mathrm{p}=0.90$ \\
\hline $\begin{array}{l}\text { Temporal choroidal } \\
\text { thickness }(\boldsymbol{\mu m})\end{array}$ & $344.40 \pm 82.49$ & $328.83 \pm 79.52$ & $\mathrm{p}=0.30$ \\
\hline Foveal thickness $(\mu \mathrm{m})$ & $216.06 \pm 53.14$ & $211.65 \pm 16.60$ & $\mathrm{p}=0.54$ \\
\hline
\end{tabular}

BCVA: Best Corrected Visual Acuity BD: Behçet's Disease. Values are presented as Mean \pm Standard deviation.

When the patients with BD were evaluated with structural SD-OCT findings, two eyes had epiretinal membrane (ERM), 4 eyes (6.7\%) had RPE-BM defect, 2 eyes (3.3\%) had Ellipsoid Zone defect, 2 eyes (3.3\%) had both Ellipsoid Zone and RPE-BM complex defect.

Mean foveal thickness in patients with BD was $216.06 \pm$ $53.14 \mu \mathrm{m}$ and mean subfoveal choroidal thickness was $363.21 \pm 85.22 \mu \mathrm{m}$. Mean foveal thickness in the control group was $211.65 \pm 16.60 \mu \mathrm{m}$ and mean subfoveal choroidal thickness was $352.83 \pm 87.11 \mu \mathrm{m}$. No statistically significant difference was observed between the two groups regarding foveal and subfoveal choroidal thickness ( $p>0.05$ for both). Comparison of best corrected visual acuity and SDOCT measurements in BD patients and control group are presented in Table 2. There was no statistically significant difference between foveal thickness, subfoveal choroidal thickness, $1000 \mu \mathrm{m}$ nasal and temporal choroidal thickness in terms of BCVA in BD patients.

\section{DISCUSSION}

$\mathrm{BD}$ is a chronic vasculitis of the arteries and veins involving multiple systems and has high morbidity due to ocular involvement. In $70 \%$ of patients with $\mathrm{BD}$, inflammatory eye findings are observed (22). Eye involvement is more frequent and more severe in young adults and especially in males and is less common in females and the elderly (23). Optical Coherence Tomography may reveal some indiscernible changes which can not be seen with fundoscopy in patients who have posterior segment involvement related to Behcet's disease. In this current study, patients with BD had an increased foveal and macular choroidal thickness compared to the control group.

Although there are publications in the literature indicating BCVA is affected more in young male patients, the mean BCVA of male BD patients was $0.94 \pm 0.18$ in this study. In literature, BCVA was below 0.1 in $20-33 \%$ of eyes. In this study, only 1 (1.66\%) eye had BCVA under 0.1 .

Many factors may affect OCT measurements. Most reported causes are age, ethnic origin, diabetes mellitus, hypertension, myopia, axial length, central serous chorioretinopathy, and history of intraocular surgery $(24,25)$. In a few studies, OCT measurements revealed significant diurnal variation between measurements. In these studies, the choroidal thickness increased towards midnight and was measured thinner at noon. The difference between these measurements varies between 30 and $60 \mu \mathrm{m}(26,27)$. As mentioned before, to minimize the effect of diurnal variations on OCT measurements, we have taken all measurements at the same time of the day.

Choroidal thickness in BD in the inactive phase was found to be thicker compared to the healthy population. Also, patients who had posterior segment involvement in the inactive phase had significantly higher subfoveal choroidal thickness compared to the fellow healthy eye. There was a $15.3 \%$ decrease of mean subfoveal choroidal thickness in $\mathrm{BD}$ during the inactive phase. Along with the increase in subfoveal choroidal thickness in the acute phase of posterior uveitis in BD, vascular leakage has increased, but these findings regressed after the acute aggravation phase of posterior uveitis. This same study showed that choroidal thicknesses of BD patients in the inactive phase were found to be thicker than the healthy population. The cause of this thickening in the choroid is due to leakage in the vascular structures. No statistically significant correlation was found between the duration of uveitis and the severity of anterior or posterior inflammation and subfoveal choroidal thickness (28). Besides, some studies revealed that BD patients with posterior segment involvement had higher subfoveal choroidal thickness measured by EDI-OCT compared to the healthy population. Kim et al. reported that BD patients with posterior segment involvement in the active phase had significantly higher subfoveal choroidal thickness than in BD patients who had posterior segment involvement in the inactive phase (28). Studies evaluating BD patients who had posterior segment involvement during the inactive phase, EDI-OCT showed that subfoveal choroidal thickness and retinal thickness were significantly thinner in BD compared to the healthy population and this thinning progressed over time. Among the causes of thinning of subfoveal choroidal and retinal thickness, choroidal atrophy triggered by affected choroidal circulation secondary to recurrent posterior uveitis and choroid, which provides oxygen and metabolite support to the retina, failing to fully function was shown $(29,30)$. 
In the literature, there are some studies evaluating the Ellipsoid Zone with OCT, which has been shown to have a close relationship with BCVA. These studies evaluated the relationship between Ellipsoid Zone structural integrity and visual acuity in patients with retinal vein occlusion, retinal detachment, and macular hole (31-33). In a study by Unoki et al., the effect of Ellipsoid Zone and ELM on BCVA was evaluated in Behcet's patients during the remission phase and only the relationship between Ellipsoid Zone and BCVA was observed but the same relationship could not be demonstrated with ELM (34).

In histopathological studies, the choroidal thickness of the posterior pole was reported to be approximately $220 \mu \mathrm{m}$ (35). In a study by Karampelas et al., retinal and choroidal imaging was performed with OCT in patients with idiopathic panuveitis. In that study, OCT images revealed the effects of duration of the disease and accompanying cystoid macular edema on visual acuity and retinal and choroidal changes. Also, that study revealed retinal and choroidal thickness and BCVA are not related (36). In a study by laccarino et al., no correlation between BCVA and choroidal thickness in patients who had posterior uveitis secondary to Behcet's disease was found (37). In another study, where 21 eyes of 21 patients with inactive idiopathic panuveitis were compared with the healthy group, choroidal thickness was correlated with the severity of the disease. However, the average choroidal thickness of affected eyes was thinner in contrast to the control group. The reason for this thinning was the thinning of the Haller's layer and hyporeflectivity as a result of loss of luminal spaces in choroidal vasculature (36). Histopathological studies have shown diffuse and focal infiltration of inflammatory cells such as CD4+ T cells, macrophages, and immunoglobulin and complement accumulation in choroidal tissue $(3,38-40)$. Various clinical features may be observed with conventional imaging systems including FA and ICGA in patients with Behcet uveitis $(9,41,42)$. As a result of leukocyte infiltration in choroidal vascular inflammation, choroidal hyperfluorescence, dye leakage or choroidal vessel wall staining may be seen $(43,44)$. As a result of the accumulation of exudative material in the stroma, edema, and fibrosis or choroidal vascular obstruction, hypofluorescence and choroidal filling defects may be seen $(42,43,45)$. Furthermore, the relationship between increased blood flow and vascular resistance and ocular perfusion pressure and choroidal thickness may also cause choroidal thickening in the active phase of inflammation $(46,47)$. Thus, the accumulation of exudates due to changes in ocular blood flow caused by choroidal vascular inflammatory reaction might also lead to choroidal thickening (28). In this current study, we observed that the pathophysiological changes in choroidal tissue may cause choroidal thickening as indicated in some studies in the literature and we found that choroidal thickness was increased in Behcet's patients.

\section{CONCLUSION}

Inclusion of only a small heterogenous, cross-sectional group of Behçet's patients, some patients receiving medical treatment prior to the participation in the study, and SDOCT measurements being taken without considering any diurnal variations are amongst the limitations of this study. Further studies with larger sample sizes are needed to elucidate the relationship between foveal thickness, macular choroidal thickness, and BCVA. In conclusion, even though patients with BD had an increased foveal and macular choroidal thickness compared to the control group, we observed no statistically significant difference in terms of foveal thickness and macular choroidal thickness.

Funding: This study was funded by Cumhuriyet University Scientific Research Projects with project number T-622.

\section{REFERENCES}

[1] Behcet $H$. Uber rezidivierende, aphthose, durchein Virus verusachte Gaschwure am Mund, am Auge und an den Genitalien. Dermat Wochsch 1937;105:1152-1157.

[2] Mittal A, Velaga SB, Falavarjani KG, Nittala MG, Sadda SR. Choroidal thickness in non-ocular Behçet's disease-A spectraldomain OCT study. J Curr Ophthalmol 2017;29(3):210-213.

[3] Charteris D, Barton K, McCartney A, Lightman S. CD4+ Lymphocyte Involvement in Ocular Behcet's Disease. Autoimmunity 1992;12(3):201-206.

[4] Gürler A, Boyvat A, Türsen U. Clinical manifestations of Behçet's disease: an analysis of 2147 patients. Yonsei Med J 1997;38(6):423-427.

[5] Kitaichi N, Miyazaki A, Iwata D, Ohno S, Stanford MR, Chams $\mathrm{H}$. Ocular features of Behçet's disease: an international collaborative study. Br J Ophthalmol 2007;91(12):1579-1582.

[6] Özdal P, Ortac S, Taşkintuna I, Firat E. Posterior segment involvement in ocular Behçet's disease. Eur J Ophthalmol 2002;12(5):424-431.

[7] Tugal-Tutkun I, Onal S, Altan-Yaycioglu R, Altunbas HH, Urgancioglu M. Uveitis in Behçet disease: an analysis of 880 patients. Am J Ophthalmol 2004;138(3):373-380.

[8] Kim HB. Ophthalmologic manifestation of Behçet's disease. Yonsei Med J 1997;38(6):390-394.

[9] Atmaca L, Sonmez P. Fluorescein and indocyanine green angiography findings in Behçet's disease. $\mathrm{Br} J$ Ophthalmol 2003;87(12):1466-1468.

[10] Gedik Ş, Akova YA, Yilmaz G, Bozbeyoğlu S. Indocyanine Green and Fundus Fluorescein Angiographic Findings in Patients with Active Ocular Behçet's Disease. Ocul Immunol Inflamm 2005;13(1):51-58.

[11] Kansu T, Kadayifcilar S. Visual aspects of Behçet's disease. Curr Neurol Neurosci Rep 2005;5(5):382-388.

[12] Klaeger AJ, Tran VT, Hiroz CA, Morisod L, Herbort CP. Use of ultrasound biomicroscopy, indocyanine green angiography and HLA-B51 testing as adjunct methods in the appraisal of Behcet's uveitis. Int Ophthalmol 2004;25(1):57-63.

[13] Tekeli O, Özdemir Ö. Heidelberg retina tomograph in ocular Behçet's disease. Eye 2004;18(2):143-146. 
[14] Alm A, Bill A. Ocular and optic nerve blood flow at normal and increased intraocular pressures in monkeys (Macaca irus): a study with radioactively labelled microspheres including flow determinations in brain and some other tissues. Exp Eye Res 1973;15(1):15-29.

[15] Laviers H, Zambarakji H. Enhanced depth imaging-OCT of the choroid: a review of the current literature. Graefe's Archive for Clinical and Experimental Ophthalmology 2014;252(12):18711883.

[16] Chung SE, Kang SW, Lee JH, Kim YT. Choroidal thickness in polypoidal choroidal vasculopathy and exudative age-related macular degeneration. Ophthalmology 2011;118(5):840-845.

[17] Fujiwara T, Imamura Y, Margolis R, Slakter JS, Spaide RF. Enhanced depth imaging optical coherence tomography of the choroid in highly myopic eyes. Am J Ophthalmol 2009;148(3):445-450.

[18] Imamura Y, Fujiwara T, Margolis R, Spaide RF. Enhanced depth imaging optical coherence tomography of the choroid in central serous chorioretinopathy. Retina 2009;29(10):14691473.

[19] Margolis R, Spaide RF. A pilot study of enhanced depth imaging optical coherence tomography of the choroid in normal eyes. Am J Ophthalmol 2009;147(5):811-815.

[20] Nakai K, Gomi F, Ikuno Y, Yasuno Y, Nouchi T, Ohguro N, Nishida K. Choroidal observations in Vogt-Koyanagi-Harada disease using high-penetration optical coherence tomography. Graefe's Archive for Clinical and Experimental Ophthalmology 2012;250(7):1089-1095.

[21] Park UC, Cho IH, Moon SW, Yu HG. Long-term change of subfoveal choroidal thickness in Behçet's Disease patients with posterior uveitis. Ocul Immunol Inflamm 2018;26(3):397405.

[22] Criteria for diagnosis of Behçet's Disease. International study group for Behcet's disease. Lancet 1990;335(8697):10781080.

[23] Yazici H, Başaran G, Hamuryudan V, Hizli N, Yurdakul S, Mat C, Tüzün Y, Özyazgan Y, Dimitriyadis I. The ten-year mortality in Behçet's syndrome. Rheumatology 1996;35(2):139-141.

[24] Alwassia AA, Adhi M, Zhang JY, Regatieri CV, Al-Quthami A, Salem D, Fujimoto JG, Duker JS. Exercise-induced acute changes in systolic blood pressure do not alter choroidal thickness as measured by a portable spectral-domain optical coherence tomography device. Retina 2013;33(1):160.

[25] Koizumi H, Yamagishi T, Yamazaki T, Kawasaki R, Kinoshita S. Subfoveal choroidal thickness in typical age-related macular degeneration and polypoidal choroidal vasculopathy. Graefe's Archive for Clinical and Experimental Ophthalmology 2011;249(8):1123-1128.

[26] Brown JS, Flitcroft DI, Ying G-s, Francis EL, Schmid GF, Quinn GE, Stone RA. In vivo human choroidal thickness measurements: evidence for diurnal fluctuations. Invest Ophthalmol Vis Sci 2009;50(1):5-12.

[27] Tan CS, Ouyang $Y$, Ruiz H, Sadda SR. Diurnal variation of choroidal thickness in normal, healthy subjects measured by spectral domain optical coherence tomography. Invest Ophthalmol Vis Sci 2012;53(1):261-266.

[28] Kim M, Kim H, Kwon HJ, Kim SS, Koh HJ, Lee SC. Choroidal thickness in Behcet's uveitis: an enhanced depth imagingoptical coherence tomography and its association with angiographic changes. Invest Ophthalmol Vis Sci 2013;54(9):6033-6039.
[29] Coskun E, Gurler B, Pehlivan Y, Kisacik B, Okumus S, Yayuspayı R, Ozcan E, Onat AM. Enhanced depth imaging optical coherence tomography findings in Behcet disease. Ocul Immunol Inflamm 2013;21(6):440-445.

[30] Takeuchi M, Iwasaki T, Kezuka T, Usui Y, Okunuki Y, Sakai Ji, Goto H. Functional and morphological changes in the eyes of Behcet's patients with uveitis. Acta Ophthalmol (Copenh) 2010;88(2):257-262.

[31] Landa G, Gentile RC, Garcia PM, Muldoon TO, Rosen RB. External limiting membrane and visual outcome in macular hole repair: spectral domain OCT analysis. Eye (Lond) 2012;26(1):61-69.

[32] Wakabayashi T, Oshima Y, Fujimoto H, Murakami Y, Sakaguchi $\mathrm{H}$, Kusaka S, Tano Y. Foveal microstructure and visual acuity after retinal detachment repair: imaging analysis by Fourierdomain optical coherence tomography. Ophthalmology 2009;116(3):519-528.

[33] Domalpally A, Peng Q, Danis R, Blodi B, Scott IU, Ip M. Association of outer retinal layer morphology with visual acuity in patients with retinal vein occlusion: SCORE Study Report 13. Eye (Lond) 2012;26(7):919-924.

[34] Unoki N, Nishijima K, Kita M, Hayashi R, Yoshimura N. Structural changes of fovea during remission of Behçet's disease as imaged by spectral domain optical coherence tomography. Eye 2010;24(6):969-975.

[35] Guyer D, Schachat A, and Green W. The choroid: structural considerations. Retina 2006;4(1):33-42.

[36] Karampelas M, Sim DA, Keane PA, Zarranz-Ventura J, Patel PJ, Tufail A, Westcott M, Lee R, Pavesio CE. Choroidal assessment in idiopathic panuveitis using optical coherence tomography. Graefe's Archive for Clinical and Experimental Ophthalmology, 2013;251(8):2029-2036.

[37] laccarino G, Cennamo G, Forte R, Cennamo G. Evaluation of posterior pole with echography and optical coherence tomography in patients with Behçet's disease. Ophthalmologica 2009;223(4):250-255.

[38] Charteris DG, Champ C, Rosenthal AR, Lightman SL. Behçet's disease: activated T lymphocytes in retinal perivasculitis. $\mathrm{Br} \mathrm{J}$ Ophthalmol 1992;76(8):499-501.

[39] George RK, Chan C-C, Whitcup SM, Nussenblatt RB. Ocular immunopathology of Behçet's disease. Surv Ophthalmol 1997;42(2):157-162.

[40] Mullaney J, Collum L. Ocular vasculitis in Behçet's disease. Int Ophthalmol 1985;7(3-4):183-191.

[41] Bozzoni-Pantaleoni F, Gharbiya M, Pirraglia MP, Accorinti M, Pivetti-Pezzi P. Indocyanine green angiographic findings in Behçet disease. Retina 2001;21(3):230-236.

[42] Matsuo T, Sato Y, Shiraga F, Shiragami C, and Tsuchida Y. Choroidal abnormalities in Behçet disease observed by simultaneous indocyanine green and fluorescein angiography with scanning laser ophthalmoscopy. Ophthalmology 1999;106(2):295-300.

[43] Herbort CP, LeHoang P, Guex-Crosier Y. Schematic interpretation of indocyanine green angiography in posterior uveitis using a standard angiographic protocol. Ophthalmology 1998;105(3):432-440.

[44] Matsuda N, Ogura Y, Nishiwaki H, Miyamoto K, Matsubara T, Kiryu J, Honda Y. Visualization of leukocyte dynamics in the choroid with indocyanine green. Invest Ophthalmol Vis Sci 1996;37(11):2228-2233. 
[45] Klaeger A, Tran TV, Hiroz C-A, Morisod L, Herbort CP. Indocyanine green angiography in Behçet's uveitis. Retina 2000;20(3):309-314.

[46] Akçar N, Göktekin F, Özer A, Korkmaz C. Doppler sonography of ocular and carotid arteries in Behçet patients. J Clin Ultrasound 2010;38(9):486-492.
[47] Kim M, Kim SS, Kwon HJ, Koh HJ, Lee SC. Association between choroidal thickness and ocular perfusion pressure in young, healthy subjects: enhanced depth imaging optical coherence tomography study. Invest Ophthalmol Vis Sci 2012;53(12):7710-7717.

How to cite this article: Bozali E, Erdogan H, Dursun A, Vural Ozec A, Toker MI, Arici MK. Evaluation of Foveal Thickness and Macular Choroidal Thickness with Optical Coherence Tomography in Behcet's Disease. Clin Exp Health Sci 2021; 11: 296-301. DOI: 10.33808/ clinexphealthsci.764833 